\title{
Delay Computation Using Fuzzy Logic Approach
}

\author{
Pandey M.K. \\ ITM University, Gwalior, M.P., India \\ Email:mukesh6776@yahoo.com \\ Dandotiya A. \\ MITS, Gwalior, M.P., India \\ Email: alokdandotiya@yahoo.com \\ Trivedi M.K. \\ MITS, Gwalior, M.P., India \\ Bhadoriya S.S. \\ SGSITS, Indore, M.P., India \\ Ramasesh G. R. \\ ITM, Gwalior, M.P., India
}

\begin{abstract}
The paper presents practical application of fuzzy sets and system theory in predicting delay, with reasonable accuracy, a wide range of factors pertaining to construction projects. In this paper we shall use fuzzy $\log$ ic to predict delays on account of Delayed supplies and Labor shortage. It is observed that the project scheduling software use either deterministic method or probabilistic method for computation of schedule durations, delays, lags and other parameters. In other words, these methods use only quantitative inputs leaving-out the qualitative aspects associated with individual activity of work. The qualitative aspect viz., the expertise of the mason or the lack of experience can have a significant impact on the assessed duration. Such qualitative aspects do not find adequate representation in the Project Scheduling software. A realistic project is considered for which a PERT chart has been prepared using showing all the major activities in reasonable detail. This project has been periodically updated until its completion. It is observed that some of the activities are delayed due to extraneous factors resulting in the overall delay of the project. The software has the capability to calculate the overall delay through CPM (Critical Path Method) when each of the activity-delays is reported. We shall now demonstrate that by using fuzzy logic, these delays could have been predicted well in advance.
\end{abstract}

Index Terms - Construction Management, Project Management, Fuzzy Logic, Fuzzy Sets \& System, Delay analysis, Computer Aided Scheduling

\section{Introduction}

Construction phase is considered as an important phase of any project. In general, timely completion of a project safeguards all parties from cost over-runs, incidental \& consequential losses, litigations etc. A good project schedule drawn out in meticulous detail is a starting point to achieve timely completion of a project. Generally it is found to be very difficult to quantify qualitative factors in terms of exact numerical values (crisp values). This paper proposed to address the important function of quantifying qualitative factors using fuzzy sets and system theory or the fuzzy logic, as we shall call it.

The concept of fuzzy logic was introduced by Zadeh in his paper on fuzzy sets [9] and presented a noncontrol methodology of partial set membership rather than crisp set membership or non-membership. In a fuzzy set, each object has its own membership value, which determines the degree to which the object belongs to a fuzzy set. Membership values range between 0 and 1. Fuzzy set proposed a theory from ordinary crisp sets with a membership value of either 0 or 1. In fuzzy sets linguistic values are quantified by the implementation of fuzzy rules. A membership function is a curve in which input space is sometimes referred to as the universe of discourse, defining how each point in the input space is mapped to a membership value between 0 and 1 . Fuzzy sets can be considered as an extension of classical or 'crisp' set theory. In crisp set theory, an element $\mathrm{x}$ is a member or non-me mber of set $A$. Thus, the membership $\mu_{\mathrm{A}}(\mathrm{x})$ of $\mathrm{x}$ into $\mathrm{A}$ is given by:

$$
\mu_{A}(x)=\left\{\begin{array}{r}
1, \text { if } x \in A \\
0, \quad \text { if } x \notin A
\end{array}\right.
$$

Let us consider that "a temperature less than $10^{\circ} \mathrm{C}$ is cold temperature .This statement in classical set as cold

$$
=\{\mathrm{x} \mid \mathrm{x} \leq 10\} .
$$




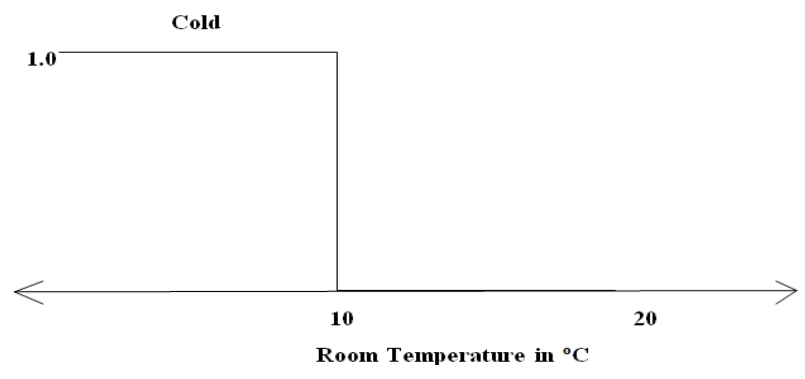

Fig. 1: Membership Function for the set (Cold Temperature)

Now "a temperature below $10^{0} \mathrm{C}$ is cold" can also be shown in fuzzy set form as shown in Fig. 2.

The concept of membership function in fuzzy sets defines blurred boundaries whereas in classical set only sharp boundaries are permitted. Fig. 2 showing a temperature of $11^{\circ} \mathrm{C}$ which can also be considered as cold as but with a less degree of membership than for $10^{\circ} \mathrm{C}(\mu \operatorname{cold}(\mathrm{x}=11)=0.85)$; but in classical set theory the degree of membership is 0 (i.e. a temperature $11^{\circ} \mathrm{C}$ does not belong to the set cold). Fuzzy set provides a tool to represent problems in everyday language, and this property provides a problem solving technique that resembles the characteristics of human reasoning and decision making.

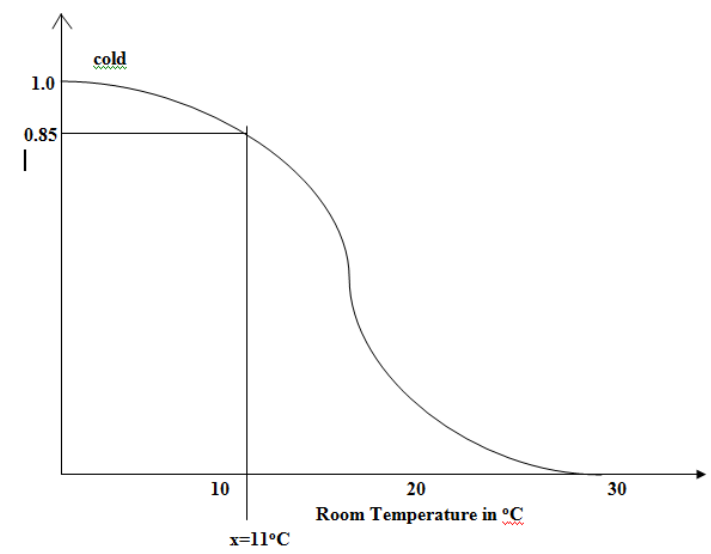

Fig. 2: Membership Function for Fuzzy Set cold temperature, $\{\mathrm{x} \mid \mathrm{x}<10\}$

In civil engineering delays in the construction project is an unavoidable circumstance. Once a delay has been experienced on an activity, then the project manager needs to find the length of delay and its effects on the remaining schedule. Delays occurring in a project result in an increase in the cost of the project, which makes it difficult to handle the project. Thus, it becomes essential to predict and identify the problems in early stages of construction.

Uncertainty arises from different aspects such as task duration, resources used and the interdependency of tasks. But in the execution process non-controllable factors such as weather, resource limitations, and managerial actions can cause alterations in the planned schedule and result in delays. Delay in critical activities or near critical activities result in project delay. So me amount of delay on non-critical-path tasks can be tolerated, but any slippage on critical-path results in delay. Project managers need appropriate tools to aid them in the process of updating the schedule based on the analysis of delays. Project managers use many techniques to handle project scheduling.

As every construction project is of complex nature to some extent. In a large and complex project, there are hundreds or thousands of activities. Construction engineers use many methods with varying degrees of complexity for project scheduling. Bar charts were early tools for project scheduling $[10,11]$ then bar charts were improved into networks, operation research techniques as linear programming, time and motion studies, simulation, work study methods, value engineering, statistical quality control, and inventory control.In itially the function of operation research was for the analysis of existing construction operations to find more efficient methods. The Critical Path Method (CPM) was first introduced, formulated and implemented on a computer to schedule construction projects in 1956 [11, 12]. Then a technique called the Program Evaluation and Review technique (PERT) was developed to coordinate contractors working on a project. It considered a Critical Path Method and depends on probability theory. PERT enables to plan and control projects by knowing the probability of occurrence of events. A new method called Graphical Evaluation and Review Techniques (GERT) was developed recently. GERT shows the related operations in a construction project. Now, the use of these methods is increased due to the implementation on computers.

These methods can be broadly divided into two groups: probabilistic and deterministic. When the information to be known and needed for a method is assumed during the analysis, it can be considered as deterministic. Bar charts and CPM classified as deterministic methods. However the information used in these methods is nondeterministic in nature. In other words a value of a parameter, such as the certain duration of an activity is not known. The uncertainty in the parameters in project scheduling leads to probabilistic methods. In these methods the parameters are generally expressed in terms of mean, standard deviation, coefficient of variation (COV) and probability distribution. The mean value indicates the average value of a parameter. The standard deviation indicates scatterness of the data from the mean value. The COV is the ratio of mean and standard deviation, and is a measure of uncertainty in the parameter .PERT and GERT are classified as probabilistic methods.

All the parameters need to be estimated weather the method is deterministic or probabilistic. Estimation of some parameters may not be done properly, since some factor affect ing these parameters cannot be quantified. Instead they are qualified. Poor, Moderate and/or excellent weather, availability or nonavailability of 
labor, procurement etc can be considered as a factor that influences the duration of an activity. Future weather conditions can be at best always hence described as poor, moderate and/or excellent. Consequently these factors were not properly incorporated in the past in the estimation of the parameters as no standard acceptable numerical value attached to qualitative statement. For example, PERT requires a subjective data interpretation of the duration for an activity in the form of three time forms (most probable, pessimistic, and optimistic values. The objective of this paper is to propose a method of incorporating qualitative factors for the estimation of delay parameter. Fuzzy set concept is considered to find the effects of qualitative factors on duration of a project. A fuzzy logic model for processing information related to an ongoing construction project and the delays encountered on the project is described. Fuzzy sets and system theory has already been successfully applied to develop solutions in the field of medicine, genetics, weather predictions, etc. The salient feature of this approach is the ingenious way in which qualitative information is manipulated to obtain quantitative outputs. The proposed paper presents the practical application of fuzzy sets and system theory in predicting delay, with reasonable accuracy, a wide range of factors pertaining to construction projects. In this paper we shall use fuzzy logic to predict delays on account of Delayed supplies and Labor shortage.

It provides useful application of fuzzy logic in solving a construction related problem, thus advancing fuzzy logic in construction project. Fuzzy logic provides project managers a tool that is capable of dealing with the uncertainties present in the nature of the delay analysis process and allows the user to make assessments using linguistic terms, which suits the actual practices commonly used in industry.

The proposed work organized in to six sections, section I contain introduction, literature survey is presented in section II, section III as case study, in section IV delay computation is given, section $\mathrm{V}$ is of result and discussion and finally followed by conclusion in section VI.

The main focus of the paper is the practical application of fuzzy sets and system theory in predicting delay, with reasonable accuracy, a wide range of factors pertaining to construction projects. Moreover, we use fuzzy logic to predict delays on account of delayed supplies and labor shortage. In addition, a realistic project is considered for which a PERT chart has been prepared using showing all the major activities in reasonable detail.

\section{Literature Survey}

It would be appropriate to mention some of the past works done by eminent researches in the field of Fuzzy Logic and its application. We express our deepest gratitude to the pioneers and other prominent researchers in this field for having provided a deep insight into the philosophy of Fuzzy Logic. While there are numerous noteworthy research papers \& contributions referred by us, we are particularly inspired by them.

Application of Fuzzy Logic in Short term Load Forecasting. Presented fuzzy concept in forecasting of load in engineering using fuzzy variables )[1]. Application of fuzzy Logic Approach for an Aircaft Model with and without Winglet [2]. Practical Application Of Fu zzy Logic from Software Engineering point of view. Described software engineering principles applied to improve the process of working with fuzzy logic and use of fuzzy logic to make artificial intelligence)[3]. Fuzzy Approach in Organizing Construction Industry Activities [4]. Analysed the operations of a concrete manufacturing plant, which produces and transports concrete to building sites. Fresh concrete is produced at a central concrete plant and transported by seven transit mixers over the distance ranging $1500-3000 \mathrm{~m}$. A fuzzy logic approach to model delays in construction projects [5] used the translational, rotational, angular, and triangular models to the fuzzy fault tree analysis, and a comparison of these four different models to find delay. A probabilistic schedule delay analysis in construction projects by using fuzzy logic incorporated with relative importance index (RII) method [6]. This research aimed to propose a decision support tool for contractors before the bidding stage to quantify the probability of schedule delay in construction projects by using fuzzy logic incorporated with relative importance index (RII) method. Fuzzy Logic approach for Activity Delay analysis and Schedule Updating [7]. Presented a fuzzy logic model for modify ing activity durations and the model integrates daily site reporting of activity progress and delays with a schedule updating and forecasting system for construction project monitoring and control. Project Scheduling Using Fuzzy Set Concepts [8]. Presented a mathe matical fuzzy model for forecasting project delay in the construction project and matching the results with the practical site delay on the live construction project.

\section{Case Study}

Our research is based on a real project executed in Gwalior (MP), India. The following project management steps are used to execute the project:

a) Prepare a detailed project schedule

b) Closely monitor the execution of the project

c) Periodically update the progress achieved

d) Highlight project delays and reasons thereof

The project schedule is prepared in reasonable detail using Micros oft Office Project 2007 shown in Fig. 3. 


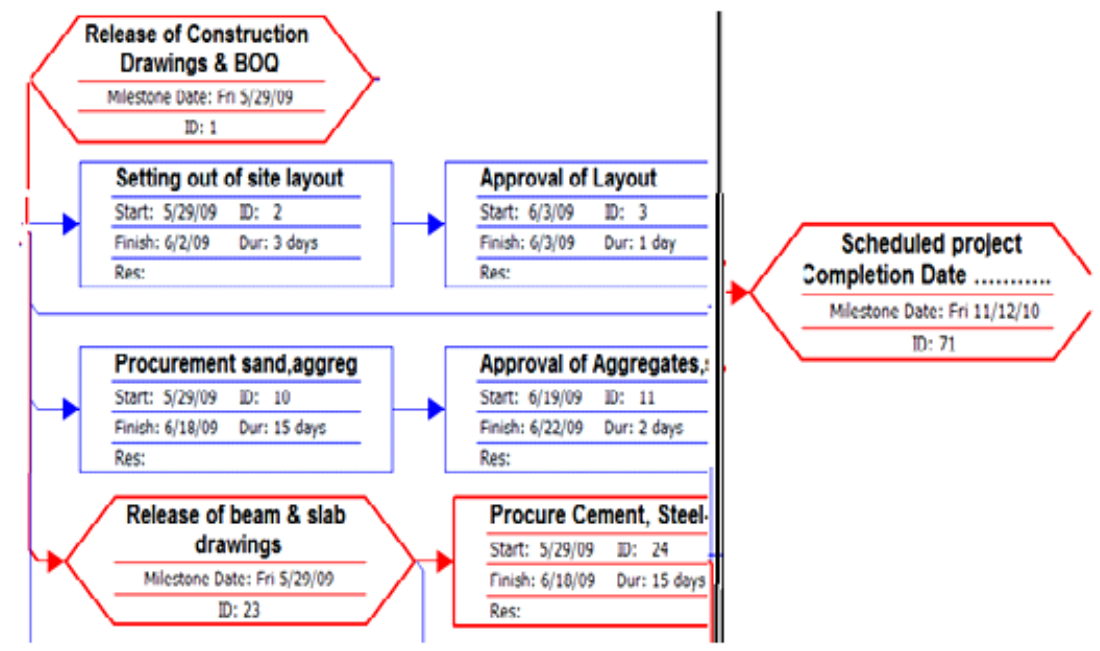

Fig. 3: The Project Schedule

\section{Delay Computation}

The following steps are involved in analyzing and predicting delays:

Step1 To demonstrate the practical application of fuzzy sets and system theory in predicting delay in the project, with reasonable accuracy, a wide range of factors pertaining to construction projects on account of delayed supplies and labor shortage. This project encountered delays on account of two distinct reasons as shown in Table 1.

Table 1: Delays and reasons thereof

\begin{tabular}{|l|l|l|l|}
\hline S. No & \multicolumn{1}{|c|}{ Reasons for delay } & \multicolumn{1}{|c|}{ Responsible } & Delay (in days) \\
\hline 1 & Shortage of Materials & Client & 13 \\
\hline 2 & Lack of Operators & Contractor & 22 \\
\hline & TOTAL DELAY (DAYS) & & $\mathbf{3 5}$ \\
\hline
\end{tabular}

Renaming the elements (Linguistic variables) appropriately so that they can be classified. For instance the first element of delay as

Procurement, since shortage of materials is directly related to the inefficiency in procurement and the second element as Labors.
The next step is to assign qualitative properties to these elements. We assigned three qualitative properties to each of these four elements namely, Poor $(\boldsymbol{P})$, Moderate $(\boldsymbol{M})$ and Excellent $(\boldsymbol{E})$ as shown in the Table 2.

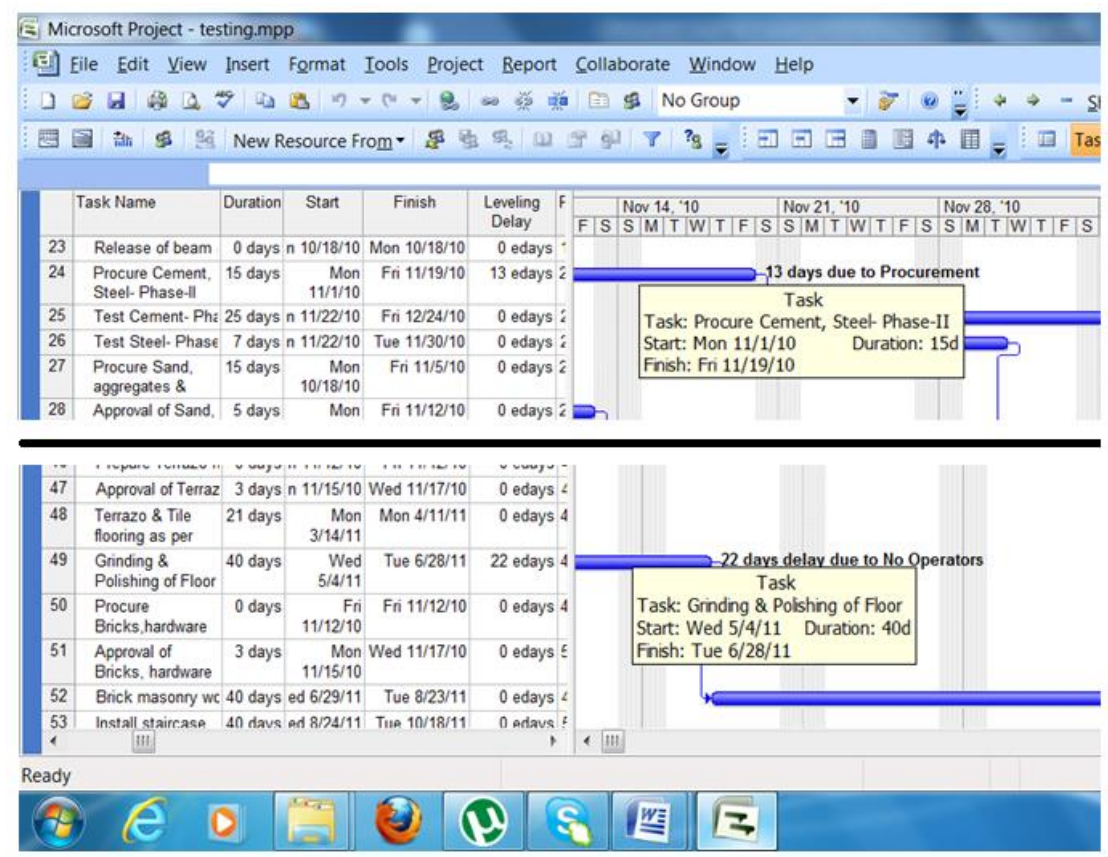


Table 2: Qualitative Properties Assigned To Elements

\begin{tabular}{|c|l|l|l|}
\hline \multirow{2}{*}{ Elements } & \multicolumn{3}{|c|}{ Properties } \\
\cline { 2 - 4 } & Poor & Moderate & Excellent \\
\hline Procurement & $\mathrm{P}$ & $\mathrm{M}$ & $\mathrm{E}$ \\
\hline Labor turnout & $\mathrm{P}$ & $\mathrm{M}$ & $\mathrm{E}$ \\
\hline
\end{tabular}

Poor indicates work of very low quality in the case of procurement. Very low labor turnout can be classified as Poor. The property Moderate applies to an intermediate situation i.e. neither too bad nor too good. This term is generally representative of the average condition. The property Excellent represents an above average situation. In a general project situation, each of these elements can occur in one of these three frequencies High $(\boldsymbol{H})$, Average $(\boldsymbol{A})$ and Low $(L)$. The adverse effect produced by each type of element properties classified as, High $(\boldsymbol{H})$-Very adversely affects the project, Average (A)-Adverse effect on project is moderate, $\operatorname{Low}(\boldsymbol{L})$ - No significant adverse effect on the project .As shown in Tables 3 and 4.

Table 3 Frequency Of Occurrence

\begin{tabular}{|c|c|c|c|}
\hline \multirow{2}{*}{ Elements } & \multicolumn{3}{|c|}{ Properties } \\
\cline { 2 - 4 } & $\mathrm{P}$ & $\mathrm{M}$ & $\mathrm{E}$ \\
\hline Procurement & $\mathrm{H}$ & $\mathrm{A}$ & $\mathrm{L}$ \\
\hline Labor turnout & $\mathrm{H}$ & $\mathrm{A}$ & $\mathrm{L}$ \\
\hline
\end{tabular}

Table 4 Adverse Effect Caused By Elements

\begin{tabular}{|c|c|c|c|}
\hline \multirow{2}{*}{ Elements } & \multicolumn{3}{|c|}{ Properties } \\
\cline { 2 - 4 } & Poor & Mod & Excellent \\
\hline Procurement & $\mathrm{H}$ & $\mathrm{A}$ & $\mathrm{L}$ \\
\hline Labor turnout & $\mathrm{H}$ & $\mathrm{L}$ & $\mathrm{L}$ \\
\hline
\end{tabular}

Now assign a numerical range of values to each of the entities defined above namely, property types $\boldsymbol{P}, \boldsymbol{M}$, $\boldsymbol{E}$, frequency of occurrence $\boldsymbol{H}, \boldsymbol{A}, \boldsymbol{L}$ and the adverse effect $\boldsymbol{H}, \boldsymbol{A}, \boldsymbol{L}$.

To compute the delay, the mathematical approach used in this study is of Bilal M. Ayyub and Achintya Haldar)[8].In the present study, the Linguistic variables and their values are changed with a minor modification in the membership function which are according to our considering project.

Step 2 Linguistic variables and membership functions are assumed as:

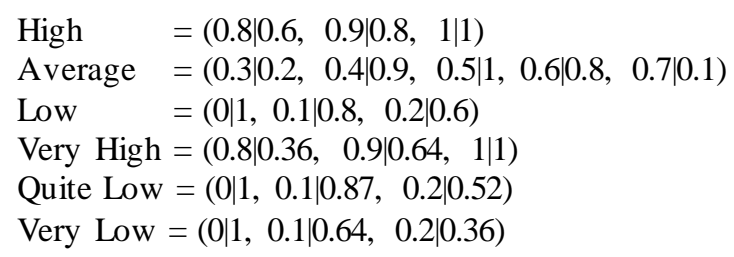

Step 3 The elements of matrix R (F x C) are calculated from (1).

The relation $\mathrm{R}(\mathrm{F}, \mathrm{C})=\mathrm{F} \times \mathrm{C}$, shows the relation between frequency and adverse effects for the delay.
The range of $\mathrm{F} \& \mathrm{C}$ is divided into the increments of 0.1 to define the linguistic variables.

$$
\mu_{R}\left(x_{i}, y_{j}\right)=\min \left[\mu_{F}\left(x_{i}\right), \mu_{C}\left(y_{j}\right)\right]
$$

where, $\mu_{R}\left(x_{i}, y_{j}\right)=$ me mbership value of element $\left(x_{i}, y_{j}\right)$ in fuzzy relation $\mathbf{R}$; $\min =$ minimum value; $\min \left[\mu_{\mathrm{F}}\left(\mathrm{x}_{\mathrm{i}}\right)=\right.$ membership value of element $\mathrm{x}_{\mathrm{i}}$ in fuzzy set $\mathbf{F} ; \mu_{\mathrm{C}}\left(\mathrm{y}_{\mathrm{j}}\right)=$ me mbership value of ele ment $\mathrm{y}_{\mathrm{j}}$ in fuzzy set $\mathrm{C} ; \mathrm{x}_{\mathrm{i}}=$ element of universe $\mathrm{X}$; and $\mathrm{y}_{\mathrm{j}}=$ element of universe $\mathrm{Y}$.

By combining the occurrence frequency $\mathrm{F}$ and the adverse effects $C_{\text {; }}$ the fuzzy relations are calculated as: $\mathrm{F}_{1} \mathrm{xC}_{1}, \mathrm{~F}_{2} \mathrm{xC}_{2}, \mathrm{~F}_{3} \mathrm{xC}_{3} \ldots \ldots \ldots . . . \mathrm{F}_{6} \mathrm{xC}_{6}$

Step 4 The union matrix T, between the fuzzy relation matrices $\mathrm{R}(\mathrm{F}, \mathrm{C})$ is computed as follows:

$$
\mathrm{T}=\operatorname{Max}\left[\begin{array}{lll}
\left(\mathrm{F}_{1} \times \mathrm{C}_{1}\right) \mathrm{U}\left(\mathrm{F}_{2} \times \mathrm{C}_{2}\right) & \mathrm{U} . . \mathrm{U} & \left(\mathrm{F}_{6} \mathrm{xC}_{6}\right)
\end{array}\right]
$$

Step 5 Then to establish a relation between subset of Consequences $\mathrm{C}$; and the subset of duration of the activity in days $\mathrm{D}$,

$\mathrm{R}: \mathrm{D}=$ Large $=(15|0.0,25| 0.05,30|0.65,40| 1)$, if Consequences ' $\mathrm{C}$ ' are Large

$\mathrm{R}: \mathrm{D}=$ Medium $=(15|0.0,25| 0.3,30|0.9,40| 1)$, if Consequences ' $\mathrm{C}$ ' are Medium

$\mathrm{R}: \mathrm{D}=$ Small $=(40|0.0,30| 0.3,25|0.6 .15| 1) \quad$, if Consequences 'C' are Small

By comparing the components of Consequences ' $\mathrm{C}$ ' $\&$ Duration ' $\mathrm{D}$ ' compute the fuzzy relation matrix $\mathrm{R}$ as:

$$
\left.\left.\mathrm{D}_{3}\right)\right\}
$$$$
\mathrm{R}=\left\{\mathrm{R}_{1}=\left(\mathrm{C}_{1} \mathrm{xD}_{1}\right)\right\} \mathrm{U}\left\{\mathrm{R}_{2}=\left(\mathrm{C}_{2} \mathrm{xD}_{2}\right)\right\} \mathrm{U}\left\{\mathrm{R}_{3}=\left(\mathrm{C}_{3} \mathrm{x}\right.\right.
$$

Step 6 Now, the estimation of the subjective duration can be calculated by composition matrix of ' $T$ ' and ' $R$ ' (Max-Min Composition) as

$$
\text { To } \mathrm{R}=\max [\min (\mathrm{T}(\mathrm{x}, \mathrm{y}), \mathrm{R}(\mathrm{y}, \mathrm{z})]
$$

Step 7 The mathe matical concept explained above has prepared in the computer programming of $\mathrm{C}++$ language, in which the input are the values for Linguistic variables (High, Average and Low) followed by the input of Possible duration for the activity and the consequences(High, Average and Low).

The result obtained by this computer programming showing all the matrices for the delay analysis. 

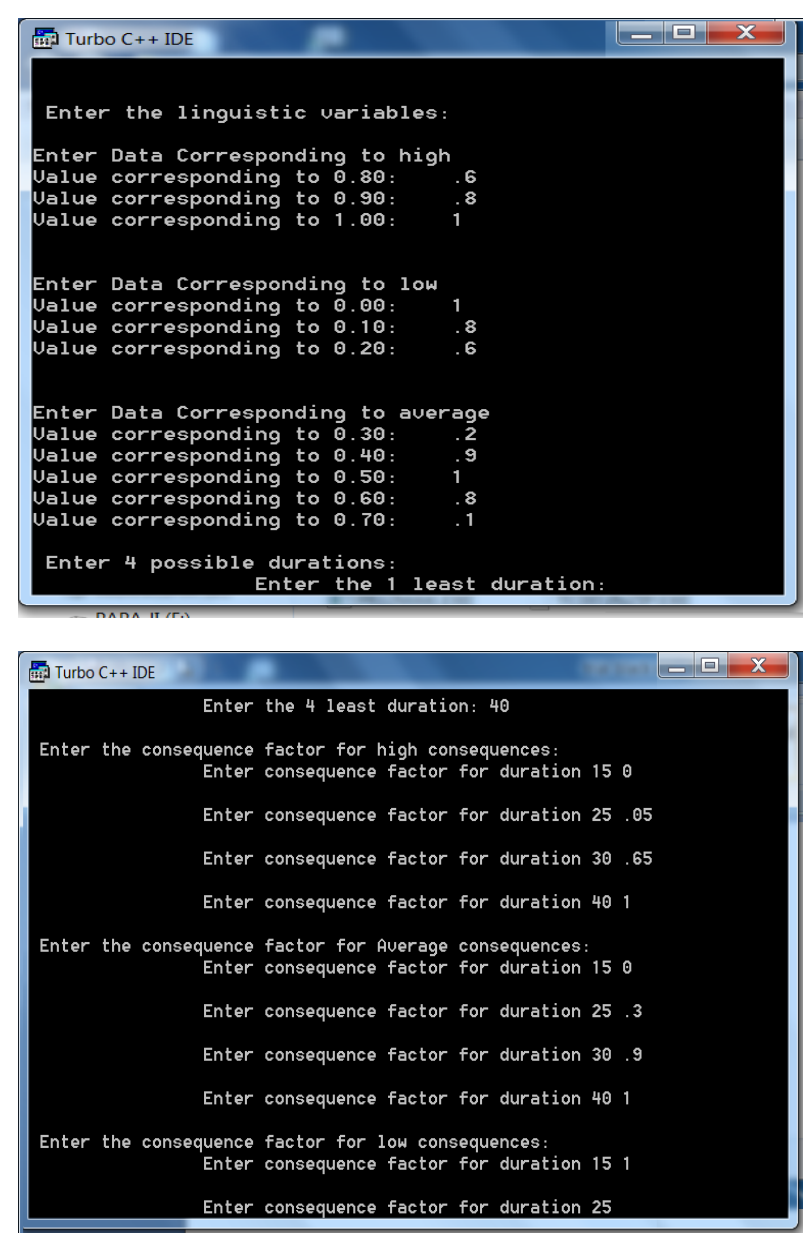

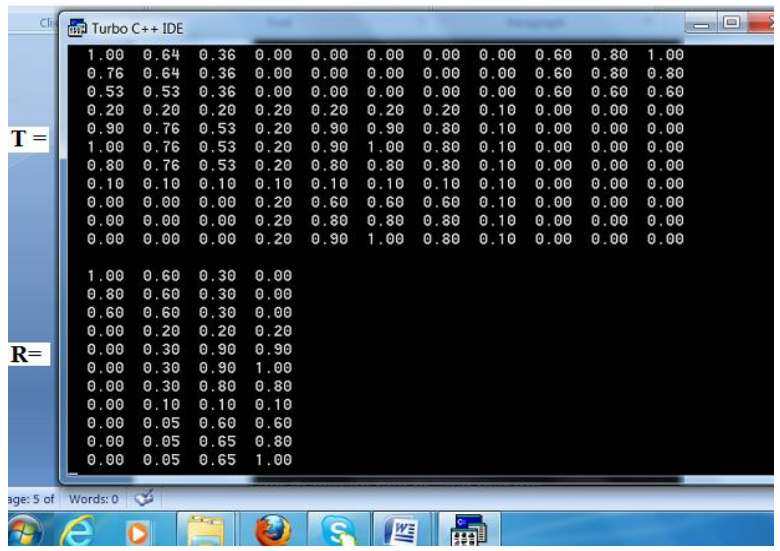

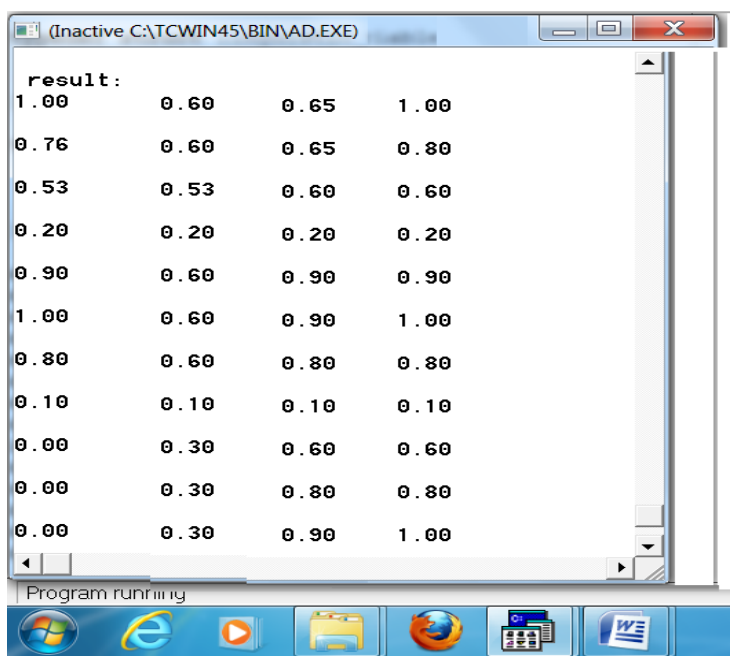

Composition Matrix ( $\mathrm{T}$ o R) is formed using equation (4) as:

\begin{tabular}{|c|c|c|c|c|c|c|}
\hline \multirow{2}{*}{ Frequency } & \multicolumn{4}{|c|}{ Delay Duration } & \multirow{2}{*}{$\begin{array}{c}\text { Summation of } \\
\text { Rows }\end{array}$} & \multirow{2}{*}{$\begin{array}{l}\text { Product } \\
\text { of Col.1 } \\
\& \text { Col.6 }\end{array}$} \\
\hline & 15 & 25 & 30 & 40 & & \\
\hline 1 & 2 & 3 & 4 & 5 & 6 & 7 \\
\hline 0 & 1.00 & 0.60 & 0.65 & 1.00 & 3.25 & 0.000 \\
\hline .1 & 0.76 & 0.60 & 0.65 & 0.80 & 2.81 & 0.281 \\
\hline .2 & 0.53 & 0.53 & 0.60 & 0.60 & 2.26 & 0.452 \\
\hline .3 & 0.20 & 0.20 & 0.20 & 0.20 & 0.80 & 0.240 \\
\hline .4 & 0.90 & 0.60 & 0.90 & 0.90 & 3.30 & 1.320 \\
\hline .5 & 1.00 & 0.60 & 0.90 & 1.00 & 3.50 & 1.750 \\
\hline .6 & 0.80 & 0.60 & 0.80 & 0.80 & 3.00 & 1.800 \\
\hline .7 & 0.10 & 0.10 & 0.10 & 0.10 & 0.40 & 0.280 \\
\hline .8 & 0.00 & 0.30 & 0.60 & 0.60 & 1.50 & 1.200 \\
\hline .9 & 0.00 & 0.30 & 0.80 & 0.80 & 1.90 & 1.710 \\
\hline 1 & 0.00 & 0.30 & 0.90 & 1.00 & 2.20 & 2.200 \\
\hline
\end{tabular}

For the computation for the average delay duration, consider the Fuzzy subset corresponding to the maximum product of column -7 in the composition matrix [8]:

The probability mass function of the activity duration is computed [9] as

$$
\begin{array}{ll}
\mathrm{P}(\mathrm{D}=15)=0 /(0+0.3+0.9+1) & =0.000 \\
\mathrm{P}(\mathrm{D}=25)=0.3 /(0+0.3+0.9+1) & =0.136 \\
\mathrm{P}(\mathrm{D}=30)=0.9 /(0+0.3+0.9+1) & =0.409 \\
\mathrm{P}(\mathrm{D}=40)=1 /(0+0.3+0.9+1) & =0.454
\end{array}
$$




\section{Average Delay Duration}

$15 \times\{0.00\}+25 \times\{0.136\}+30 \times\{.409\}+40 \times\{0.454\}$ $=33.83$ days

\section{Result And Discussion}

The delay duration computed using the fuzzy logic approach is 33.83 days which is nearly equal to the actual delay occurred in the considering realistic housing project, which shows that the applied approach to predicting delay is practically correct.

\section{Conclusion}

This paper deals with the practical approach for the computation of delay in the construction of housing project using fuzzy logic approach considering a realistic project. The mathematical approach in this paper is implemented to the computer programming of $\mathrm{C}++$ language, in which the input are the values for Linguistic variables followed by the input of Possible duration for the activity and the consequences, which may used by the practitioners, researchers in the construction industry for predicting delay in the housing project due to qualitative aspects associated with the individual activity of project.

\section{Acknowledgments}

Our special thanks to Mr. Brijesh Kumar Chaurasia and contractors, who have contributed towards development of this research work.

\section{References}

[1] Abhishek Nayak \& Bharat Mahendru. Application of Fuzzy Logic in Short term Load Forecasting, (2012), pp.1-10.

[2] Altab Hossain, Ataur Rahman, Jakir Hossen, A.K.M.P Iqbal, and S.K. Hasan. Application of fuzzy Logic Approach for an Aircaft Model with and without Winglet, (2011), pp.224-228.

[3] Norbert Sram, Obuda University, Budapest. Practical Application Of Fuzzy Logic from Software Engineering point of view,(2011), pp.285-291.

[4] ] S. Petrovic-Lazarevic and A. Abraham. Fuzzy Approach in Organizing Construction Industry Activities,(2002), pp.1-22.

[5] Hanouf M. Al-Humaidi. The Ohio State University "Fuzzy logic approach to model delays in construction projects",(2007), pp.1-202.

[6] Mustafa Özdemir. "A probabilistic schedule delay analysis in construction projects by using fuzzy logic incorporated with relative importance index (RII) method", (2010), pp.1-112.

[7] Adriana V. Ordonez Oliveros and Aminah Robinson Fayek. "Fuzzy Logic approach for Activity Delay analysis and Schedule Updating",(2005), pp. 42-51.

[8] Bilal M. Ayyub and Achintya Haldar. "Project Scheduling Using Fuzzy Set Concepts". "J. Constr. Eng. Manage.,(1984), pp. 110(2), 189-204.

[9] L.A. Zadeh. "Fuzzy sets," Information and Control, Vol.8, (1965), pp. 338-353.

[10] R. W. Miller. Schedule Cost and Profit Control with PERT, McGraw-Hill Book Co., New York, N.Y. (1963).

[11] J.J. O'Bre in. Scheduling Handbook, Mc Graw-Hill Book Co., New York, N.Y., (1969).

[12] H.N. Ahuja. Construction Performance Control by Network, John Wiley \& Sons, inc., New York. (1976), pp. 23-126.

\section{Authors' Profiles}

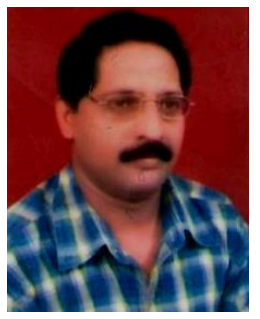

Mukesh Pandey is pursuing Ph. D. from R.G.P.V, Bhopal, M.P. India in Civil Engineering. He has M.E. in C.T.M from M.I.T.S, Gwalior, M.P., India. Currently he is Associate Professor, Civil Engineering Department, ITM-U, Gwalior, M.P., India.

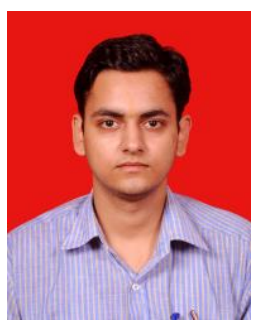

Alok Dandotiya is pursuing M.E C.T.M from M.I.T.S. Gwalior,M.P., India in Civil Engineering. He is a Research Scholar, Civil Engineering Department, M.I.T.S., Gwalior, M.P., India.

How to cite this paper: Pandey M.K., Dandotiy a A., Trivedi M.K., Bhadoriy a S.S., Ramasesh G. R.,"Delay Computation Using Fuzzy Logic Approach", International Journal of Intelligent Systems and Applications(IJISA), vol.4, no.11, pp.84-90, 2012. DOI: 10.5815/ijisa.2012.11.10 